\title{
FAMILIAS EN LA ENCRUCIJADA. \\ REDES SOCIALES, LEALTADES Y RESISTENCIAS DURANTE \\ LA GUERRA DE SUCESIÓN (PAÍS VASCO Y NAVARRA, 1680-1715)*
}

FAMILIES CROSSROADS. SOCIAL NETWORKS, LOYALTIES AND
RESISTANCES DURING
THE SUCCESSION WAR (BASQUE COUNTRY AND NAVARRE, 1680-1715)

FAMÍLIAS NO ENCRUZILHADA.
REDES SOCIAIS, LEALDADES E RESISTÊNCIAS DURANTE
A GUERRA DE SUCESSÃO (PAÍS BASCO E NAVARRA, 1680-1715)

RAFAEL GUERRERO ELECALDE***

Universidad de Córdoba, España

https://doi.org/10.46553/EHE.23.2.2021.p121-139

\begin{abstract}
Resumen
A través de una metodología en clave de red social nos preguntaremos cómo se fueron definiendo y conformando los bandos elites durante la Guerra de Sucesión. Tradicionalmente, se ha establecido que la Monarquía quedó dividida entre los reinos de la Corona de Aragón, partidarios del archiduque Carlos y los territorios de Castilla, defensores de Felipe V. Sin embargo, ni mucho menos parece que fueron bloques monolíticos. Para demostrarlo, se tomará como piedra de toque las elites de las provincias vascas y Navarra. La hipótesis de partida reside en que estas fidelidades están íntimamente relacionadas con los vínculos que estas familias estaban manteniendo a lo largo del tiempo con aquellos que están liderando cada uno de los bandos de la guerra. Asimismo, estos posicionamientos conllevaron la movilización de personas y recursos a favor de uno u otro pretendiente, lo que fue pieza clave para el devenir del conflicto bélico.
\end{abstract}

Palabras claves

Guerra de Sucesión, siglo XVIII, redes sociales, Historia Social, correspondencia

\begin{abstract}
Through a social network key methodology, we will ask ourselves how the elite groups were defined and shaped during the War of Succession. Traditionally, it has been established that the Monarchy was divided between the kingdoms of the Crown of Aragon, supporters of Archduke Carlos and the territories of Castile, defenders of Felipe V. However, they do not seem to have been monolithic blocks. To demonstrate this, the elites of the Basque provinces and Navarra will be taken as a sample. The starting hypothesis is that these loyalties are closely related to the ties that these families were maintaining over time with those who were leading each side of the war. Likewise, these positions led to the mobilization of people and resources in favor of one or another suitor, which was a key piece for the future of the war.
\end{abstract}

\section{Keywords}

Succession War, 18th century, social networks, Social History, correspondence 


\section{Resumo}

Por meio de uma metodologia-chave de rede social, nos perguntaremos como os grupos de elite foram definidos e modelados durante a Guerra da Sucessão. Tradicionalmente, foi estabelecido que a Monarquia era dividida entre os reinos da Coroa de Aragão, partidários do arquiduque Carlos e os territórios de Castela, defensores de Felipe V. No entanto, não parece muito menos que fossem blocos monolíticos. Para demonstrar isso, as elites das províncias bascas e Navarra serão consideradas uma pedra de toque. A hipótese inicial é que essas lealdades estão intimamente relacionadas aos laços que essas famílias mantinham ao longo do tempo com aqueles que lideram cada lado da guerra. Da mesma forma, essas posições levaram à mobilização de pessoas e recursos em favor de um ou outro pretendente, que foi uma peça fundamental para o futuro da guerra.

\section{Palavras-chave}

Guerra de Sucessão, século XVIII, redes sociais, História Social, correspondência

\section{Introducción}

La definitiva disposición de Carlos II a favor del joven duque de Anjou acarreó agravios y compensaciones entre las potencias europeas que solo se podrían resolver a través de una guerra. ${ }^{1}$ No solo se trató de dos pretendientes que pugnaron por ocupar el trono español, sino que también fueron dos modelos de entender el gobierno de la Monarquía. De este modo se comprende la configuración de sus administraciones y los diferentes perfiles de los gobernantes. ${ }^{2}$

Tradicionalmente, durante la Guerra de Sucesión, se ha planteado que los bandos se dividieron entre los reinos de la Corona de Aragón, partidarios del archiduque Carlos y los territorios de Castilla, defensores de la legitimidad de Felipe V de Borbón. Aunque principalmente esta afirmación tiene fundamento porque las corporaciones de estos espacios proclamaron y defendieron jurídicamente su legítima defensa de uno u otro candidato, ni mucho menos debemos entender que las familias se trataron de bloques monolíticos, ya que se produjeron divergencias entre las casas más poderosas de estos territorios. Igualmente, los trabajos se han dedicado especialmente a estudiar los discursos políticos, así como los conflictos religiosos que generó por la toma de partidos de holandeses e ingleses. ${ }^{3}$

Por eso mismo, en este mundo en construcción, los agentes del rey fueron reconstruyendo sus vínculos al mismo tiempo que se fue rediseñando el gobierno de la Monarquía, dirigida tanto al reforzamiento de la presencia del soberano en los distintos espacios de poder como en sus propias necesidades derivadas por los acontecimientos bélicos y las necesidades obligadas para la victoria final de la guerra. Los lazos establecidos para el desempeño de estas políticas exigieron una atención permanente por cada uno de los protagonistas, que fueron alimentando por diferentes caminos, como los

\footnotetext{
* Fecha de recepción: 17/08/2020. Fecha de aceptación: 03/12/2020.

**Doctor en Historia y profesor en el Departamento de Didácticas Específicas, Facultad en las Ciencias de la Educación, Universidad de Córdoba, España, ORCID: https://orcid.org/0000-0003-4271-897X, Calle San Alberto Magno, s/n, 14071 Córdoba, rgelecalde@uco.es.

${ }^{1}$ CASTRO, 2004, 40; BARRIOS, 1984, 177; ESCUDERO, t.I, 1979, 32; BADORREY, 1999, 27; DESOS, 2009; KAMEN, 1974; ALBAREDA, 2010.

${ }^{2}$ DEDIEU, 2000; DESOS, 2009; LEÓN, 2014; GUERRERO ELECALDE, 2012.

${ }^{3}$ LUZZI, 2014, 135-163; KAMEN, 1974; ALBAREDA, 2010; GONZÁLEZ CRUZ, 2012; VICENT LÓPEZ, 2000, 61-82.
} 
parentescos, las intrigas palaciegas o las fidelidades a las grandes casas, a los agentes de Luis XIV o a la propia reina. Asimismo, estos posicionamientos conllevaron la movilización de personas y recursos (materiales e inmateriales) a favor de uno u otro pretendiente, lo que fue pieza clave para el devenir de la Guerra de Sucesión.

Según la experiencia obtenida en trabajos anteriores ${ }^{4}$, entendemos que estas lealtades y posturas están íntimamente relacionadas con los vínculos que estas familias y sus miembros fueron manteniendo a lo largo del tiempo con aquellos personajes poderosos de cada uno de los partidos.

Por eso mismo, desde nuestra perspectiva y para llegar a un mejor conocimiento de las causas y consecuencias, así como para ver la participación de estas elites en el gobierno y en la articulación de la Monarquía como un fenómeno de gran complejidad, se hace necesario un estudio en clave de red social. El análisis a partir de los "actores sociales reales" muestra que las actividades y acciones de las personas dependen del campo estratégico en el que se encuentran: del marco geográfico o social, de sus relaciones de oposición y afinidad con otros actores; de su posibilidad de acceder o no, en una situación dada, a un tipo determinado de recursos -económicos, militares, políticos, por ejemplo; de sus alianzas como grupos más vastos... ${ }^{5}$

Desde el siglo XVI, numerosas familias procedentes de las provincias vascas y Navarra tuvieron como ámbito de actuación los amplios territorios de la Monarquía hispánica. A lo largo de varias generaciones, y a través de una determinada política doméstica, fueron colocando según sus posibilidades y relaciones a sus vástagos desarrollando carreras en el comercio del hierro y las lanas del norte de Europa, en los negocios indianos, en las universidades y tribunales de justicia y Consejos, en los tercios de Flandes o de Italia, o en las secretarías del rey. ${ }^{6}$

En muchas ocasiones, la entrada en estos espacios vino de la mano de los cabezas de las grandes casas aristocráticas castellanas (miembros de los órganos de gobierno de la Monarquía), quienes los patrocinaron después de haberlos admitidos como parte de "su familia" para que ejercieran de secretarios y tesoreros de sus estados. ${ }^{7}$

Con el comienzo del siglo XVIII, todo fue cambiando, y estas familias hubieron de elegir entre dos pretendientes al trono español, con sus diversos modos de entender la Monarquía: Felipe V o Carlos III.

\section{Una mayoría felipista: la fuerza de los Idiáquez}

En el transcurso de la Guerra de Sucesión, las familias de las elites vascas y navarras se repartieron desigualmente entre los bandos enfrentados. Una inmensa mayoría se decantó por el candidato francés, lo que provocó que los territorios se mantuvieran fieles a Felipe V a lo largo de la contienda, participando activamente con la incorporación de hombres, armas, pertrechos, y diversas sumas de caudales. Este ha sido el grupo más estudiado y mejor conocido.

\footnotetext{
${ }^{4}$ GUERRERO ELECALDE, 2009, 247-258; 2010; 2010b, 145-176; 2012.

${ }^{5}$ GUERRA, 1993, 243-264.

${ }^{6}$ GUERRERO ELECALDE, 2012; IMÍZCOZ BEUNZA Y GUERRERO ELECALDE, 2004, 177- 238.

${ }^{7}$ GUERRERO ELECALDE, 2012, 87.
} 
Luis XIV hizo que el nuevo soberano se rodease de personas selectas para que le aconsejasen en los negocios de la Monarquía. ${ }^{8}$ Sus agentes principales en la corte de Madrid fueron su embajador, que tuvo puesto en el Consejo de Gabinete, y la Princesa de los Ursinos la cual, como camarera de la reina, se convirtió en la principal baza dentro de los espacios menos "formales" de poder. ${ }^{9}$ Estas personalidades tuvieron la misión de impulsar unas intensas reformas en la Monarquía, que se caracterizaron por la constitución de nuevas instituciones de gobierno, como fue la Secretaría del Despacho (reestructurada en un nuevo concepto), la creación de la Tesorería Mayor de Guerra o las guardias reales y de corps, y por el vaciado de poder de los tradicionales Consejos. ${ }^{10}$

En esta labor renovadora, la alta nobleza castellana se vio desplazada de los espacios de decisión a favor del ascenso de hombres nuevos, produciéndose un importante cambio en el mapa del reparto del poder. Las familias de las tradicionales casas de nobles fueron excluidas del gobierno efectivo, ya que los Consejos fueron reducidos a la mínima expresión. Asimismo, se les negaron a los grandes sus privilegios en el ejército, que vino acompañada con la constitución de las guardias reales. ${ }^{11}$

En los puestos principales de la administración, se establecieron miembros de estas familias vascas y navarras que dieron sentido a la renovada administración, a la vez que fueron participando en el gobierno de la Monarquía. ${ }^{12}$ Concretamente, la relación con la camarera de la reina fue clave para su elevación.

Desde el otro punto de vista, el de los representantes del monarca, el atractivo de estas personas no fue exclusivamente su experiencia personal en la administración o en la milicia, sino que también fue muy valioso el poder económico (vinculado especialmente con los negocios del hierro y la plata de Indias), así como la capacidad de movilizar a más gente a favor en la causa borbónica.

El caso más importante fue el de la familia Idiáquez, de Azcoitia (Guipúzcoa), que contó a Juan de Idiáquez (1665), sumiller de corps de las guardias de corps y hombre de confianza de la Princesa de los Ursinos ${ }^{13}$, como su miembro principal. Así se entendió en la corte de Versalles, tal y como lo expresó en 1704, Charmillart, secretario de Guerra de Luis XIV:

"Il n'y a que neuf jours que ce changement inspiré est arrivé en un homme qui étoit bien avant dans les bonnes grâces de son roi. Il est d'une [de las más] considérables familes qui donne le mouvement au reste de la province. Je ne sais quel effet pourra produire cet événement dans l'esprit de ses parents, qui ont toujours eu la réputation de très sages $(\ldots) "{ }^{14}$

\footnotetext{
${ }^{8}$ DEDIEU, 2000, 114; MARTÍNEZ CARDÓS, 1972, LIV; CASTELLANO, 2002, 134; CASTRO, 2004, 45; KAMEN, 1974, 371.

${ }^{9}$ GIRARDOT, 2012.

${ }^{10}$ DEDIEU, 2000, 116; ESCUDERO, 1979, 34-48; ALB AREDA, 2010, 148-164; DUBET, 2007, 207-234; DUBET, 2008, 191-216; LÓPEZ-CORDÓN, 2000, 93-111; IÑURRITEGUI, 2008; GIRARDOT, 2012.

${ }^{11}$ DEDIEU, 2000, 113-139; ANDÚJAR 2000, 65-94; ANDÚJAR, 2001, 91-122.

${ }^{12}$ Junto a ellos, foráneos (franceses, italianos, irlandeses, flamencos), la minoría de las familias de la Corona de Aragón fieles a la causa felipista y otros hombres provenientes de la periferia de la Península Ibérica (los llamados "norteños"), compuesta por asturianos, montañeses de Santander y del norte de Burgos, riojanos y sorianos. GUERRERO ELECALDE, 2012, 478.

${ }^{13}$ GIRARDOT, 2012, 208.

${ }^{14}$ Carta de Hirrigoity a Miguel Chamillart, secretario del Despacho de Guerra de Francia, Tolosa, 7 de mayo de 1705. Service Historique de l'Armée de Terre, Paris (SHAT), Série A, 1885, ex 31 bis y ex 277.
} 
Muy implicado en todos los ámbitos, pero sobre todo en el campo militar, Juan de Idiáquez influyó para introducir y elevar a parientes y allegados tanto en las guardias de infantería como en las guardias de corps. De hecho, en 1704, brindó la oportunidad a su hermano, Pedro, para que, desde Azcoitia, le seleccionase y presentase a los miembros de la parentela y de otras de familias amigas más adecuados para entrar a formar parte de los primeros cuadros de estas guardias. ${ }^{15}$ Solo fruto de estos vínculos se entiende las carreras y cargos de su hermano Tomás de Idiáquez, capitán general de la Costa de Andalucía (1725); Bruno Mauricio de Zavala, gobernador y capitán general del Río de la Plata (1716); José Basilio Aramburu Atorrasagasti, capitán general de Mallorca (1750); Gabriel José de Zuloaga, gobernador y capitán general de Venezuela (1744); Luis de Guendica y Mendieta; Francisco Lucas de Arauna y Mallea; Manuel Jacinto de Sierralta, gobernador y capitán general de la Provincia de Yucatán (1734); su hermano Miguel Fernando Salcedo Sierralta, gobernador y capitán general del Río de la Plata (1731); Francisco Ignacio de Arzamendi Lersundi, gobernador de Fuenterrabía (1744); Cristóbal de Aranda y Amézaga, gobernador de Villanueva de la Serena (Alcántara) (1747); o José Ignacio Zaldúa y Gamboa, gobernador político-militar de Alcántara (1738).

Asimismo, con la ayuda de sus hermanos y de otros colaboradores, influyó principalmente para la conformación de regimientos provinciales y la fabricación de armas. Así se demuestra con el análisis del levantamiento en 1705 del regimiento de Guipúzcoa, así como con los formados en 1709 en Vizcaya, Guipúzcoa y Álava. ${ }^{16}$ Entre todos los colaboradores que actuaron para constitución de estos cuerpos militares provinciales destacaron Bruno Mauricio de Zavala, su primo Carlos de Areizaga y, sobre todo, su hermano Tomás de Idiáquez, quien en 1705 fue el encargado, entre otras cuestiones, en "solicitar [a] mis parientes y amigos para que incesantemente trabajen en esta nueva planta y reconociendo que lo que no conseguiré su aplicación haciéndose cargo de la urgencia del tiempo en pocos días, no logrará después". ${ }^{17}$

En otro aspecto, otro de los hermanos, Antonio de Idiáquez, se carteó frecuentemente con su "amigo de corazón" Miguel Francisco de Salvador, superintendente de las Reales Fábricas de Armas de Cantabria ${ }^{18}$, para concretar estrategias y actuaciones en busca del mejor servicio a la causa borbónica. De este modo ocurrió, por ejemplo, en marzo de 1711, cuando el marqués de Canales y el Consejo de Guerra solicitaron a Guipúzcoa el abono del prest del regimiento de la provincia y 500 fusiles para su abastecimiento. Antonio, asistente en las juntas, trabajó para persuadir al resto de los participantes para que la Provincia aprobara la petición del monarca. Para ello, debió hacer valer ser uno de los miembros principales de Guipúzcoa y, como se vivían momentos complicados por la guerra, actuó con prudencia sin mostrar su alianza con el superintendente de las Reales Fábricas: ${ }^{19}$ "Acabase nuestra junta felizmente y el memorial que arreglé a las prevenciones de v.m. se decretó como en él se pedía el discurso

\footnotetext{
${ }^{15}$ Carta de Pedro de Idiáquez a Pedro Bernardo de Villarreal de Bérriz, Azcoitia, 2 de enero de 1704. Archivo de la Torre de Uriarte, Lekeitio, Bizkaia (ATU), leg. XXIV, 3-8-c, d.

${ }^{16}$ GUERRERO ELECALDE, 2012, 199-216; 314-327.

${ }^{17}$ Archivo Histórico Nacional (AHN), Estado, leg. 276.

${ }^{18}$ Con sede principal en Placencia de las Armas, Guipúzcoa.

${ }^{19}$ Carta de Antonio de Idiáquez a Miguel Francisco de Salvador, Azcoitia, 5 de abril de 1711. AHN, Estado, leg. 402.
} 
de los quinientos fusiles, aunque también fundado no propuse porque estaba hecho antes el empeño de pretender que el rey librase el prest a este regimiento". ${ }^{20}$

Como vemos, las privilegiadas posiciones de los Idiáquez en la corte y en las comunidades de origen los favorecieron para influir en los asuntos de gobierno de las provincias. De este modo, pudieron manejar la legitimidad emanada de estas instituciones en beneficio personal y de sus empresas particulares, siempre por el bien del Señorío, las provincias y Navarra o por el buen servicio al rey.

En Guipúzcoa, durante la Guerra de Sucesión salieron elegidos diputados generales varios componentes de la casa Idiáquez: Juan, entonces maestre de campo (1702) y su hermano Tomás, "estando en actual servicio de S.M." (1706), así como el sobrino Antonio de Idiáquez, "siendo al tiempo brigadier de las reales guardias de corps" (1707). Otros miembros de familias cercanas que salieron diputados generales fueron Mateo Nicolás de Aranguren y Andicano (1712); Francisco Ignacio Emparan Sorarrain (1704); el coronel Francisco José de Emparan y Azcue ${ }^{21}$ (1711); Miguel Aramburu Atorrasagasti (1708); José de Aristeguieta (1709); o Ignacio Jacinto Aguirre Eleizalde (1706 y 1711). ${ }^{22}$

También fueron influyentes en otras corporaciones, como las casas de contratación y consulados de comercio o los ayuntamientos. Respecto a los concejos, fueron elegidos durante la guerra para desempeñar los más altos empleos de estas corporaciones miembros de las familias allegadas a los Idiáquez, los cuales simultáneamente estaban desarrollando carreras en los cuadros de la administración o ejército del Borbón. Entre todos ellos podemos destacar a estos alcaldes de las villas guipuzcoanas: Francisco José de Emparan y Azcue (Azpeitia, 1705 y 1710) ${ }^{23}$; Juan de Idiáquez (Azcoitia), Juan Bautista de Orendain (Segura, 1707); Pedro Ignacio de Atorrasagasti (Andoain, 1707); Nicolás de Araoz y Lazarraga (Oñate, 1707); Juan Raimundo de Arteaga y Lazcano (Villafranca de Ordicia, 1708); Juan Ángel de Echeverría (San Sebastián, 1708).

\section{La minoría seguidora del archiduque: los vascos y navarros fieles al Almirante de Castilla}

Mucho menos conocidas son las familias vascas y navarras que decidieron jurar fidelidad a Carlos III. Las desafecciones de los grandes de España no llegaron inmediatamente, sino que se fueron produciendo paulatinamente según fueron concretando las renovaciones políticas y el ascenso de las nuevas familias. Poco a poco, las tradicionales elites gobernantes de la Monarquía se fueron desencantando de las políticas llevadas a cabo por los agentes profranceses, que les llevaron a alejarse de los órganos de poder a la vez de ser considerados sospechosos de insurrección. La defección del Almirante de Castilla en 1702 y el apresamiento del marqués de Leganés tres años después, solo fueron dos de los procesos más destacados. Con el paso del tiempo, incluso durante los años 1704 y 1705 algunos grandes encabezaron varias conspiraciones para derrocar al rey Borbón. ${ }^{24}$

\footnotetext{
${ }^{20}$ Carta de Antonio de Idiáquez a Miguel Francisco de Salvador, San Sebastián, 11 de mayo de 1711. AHN, Estado, leg. 402.

${ }^{21}$ Hijo del anterior. AHN, Estado, Carlos III, ex 510, año 1791.

${ }^{22}$ MÚGICA, 1943.

${ }^{23}$ AHN, Estado, Carlos III, ex 510, año 1791.

24 ALBALAREDA, 2010; KAMEN, 1974, 110; GONZÁLEZ MEZQUITA, 2007; GIRARDOT, 2012, 214-215, 225; AHN, Consejos, Concursos, Secuestros, 51213.1.
} 
Algunas de las familias vascas y navarras, especialmente aquellas que no lograron ganarse el patrocinio de los agentes franceses, continuaron en el servicio de sus señores, convirtiéndose también en piezas principales de los cuadros militares y administrativos de Carlos III. Se trató de una apuesta que finalmente significó en muchas ocasiones ser despojados de sus posesiones en la patria chica, e incluso los llevó al exilio en Nápoles o en Viena. ${ }^{25}$ Así, por ejemplo, parece que el número de navarros que se exiliaron a la ciudad austriaca tras la guerra no fue menor. Entre otros, Manuel de Sagesta, José de Tirapegui, Saturnino Mutiloa, Juan de Azcarate, Juan de Elizalde, Pedro de Arratea y Tomás de Arizu. ${ }^{26}$

Queda mucho por investigar en este aspecto, aunque poco a poco tenemos más datos. Así, por ejemplo, la amplia casa de Juan Tomás Enríquez Cabrera, conde de Melgar, Almirante de Castilla, que contó con numerosos criados procedentes del norte peninsular, fue un semillero de leales servidores del archiduque. ${ }^{27}$

Pariente del conde de Melgar y de los duques del Infantado, D. Diego Hurtado de Mendoza y Sandoval (Madrid, 1650) ${ }^{28}$, fue criado en la corte, entrando después en la carrera militar. Se incorporó como soldado en el ejército de Cataluña, donde fue nombrado capitán de la compañía de caballos corazas. Sirvió como tal hasta el 1685 en que S.M. le ascendió a maestro de campo de la ciudad de Granada. En 1692 fue elegido corregidor y gobernador de la ciudad y tierra de Gibraltar.

En 1696, fue nombrado gobernador de Guipúzcoa y después maestre de campo general del ejército de Cataluña. En 1697, durante el acoso que sufrió Barcelona a manos de las tropas francesas, fue nombrado virrey de Cataluña, aunque capituló casi de inmediato. Su parcialidad hacia la reina Mariana de Neoburgo le apartaron de cualquier empleo o cargo relevante, lo que también ayudó a abrazar la causa de Carlos III tempranamente. En 1702, acompañó al Almirante de Castilla a Portugal consumando su defección y, de este modo, se convirtió en uno de los primeros nobles castellanos que se decantó contra Felipe V. ${ }^{29}$

Desde entonces, fue una de las piezas clave en el gobierno del pretendiente, especialmente en el Consejo de Guerra, y en la dirección de las tropas. Sus casas en Vitoria fueron requisadas por Francisco Antonio de Aguirre y Salcedo, guardia real cercano a los Idiáquez y alcalde de la ciudad, para ser usadas como depósito de armas para la guerra. ${ }^{30}$

En 1706 acompañó a Carlos en su fallida entrada en Madrid y con la posterior retirada a Valencia fue nombrado virrey de dicho reino (1707), aunque la derrota de Almansa les obligó a retirarse a Cataluña. En 1712 el ya emperador Carlos le designó plenipotenciario en las negociaciones que sobre la guerra se mantenían en Utrecht. ${ }^{31}$

\footnotetext{
${ }^{25}$ STIFFONI, 1991, 7-56.

${ }^{26}$ QUIRÓS, 2017, 156.

${ }^{27}$ GONZÁLEZ MEZQUITA, 2007.

${ }^{28}$ Fue hijo de Esteban Hurtado de Mendoza, conde de la Corzana, caballero del hábito de Santiago, natural de Vitoria, y de Tomasa de Sandoval, nieta del primer duque de Lerma. RODRÍGUEZ VILLA, 1907, 114-115.

${ }^{29}$ KAMEN, 1974, 109, 111 y 114- 115; LEÓN SANZ, 1993, 29, 54-55, 67, 69, 191-192 у 220; RODRÍGUEZ VILLA, 1907.

${ }^{30}$ Carta del conde de la Estrella a José Grimaldo, Madrid, 12 de enero de 1710. AHN, Estado, leg. 391.

${ }^{31}$ RODRÍGUEZ VILLA, 1907.
} 
Otro de los asociados del almirante de Castilla, fue el alavés Juan de Larrea y Pérez de Henayo ${ }^{32}$, natural de Argómaniz, caballero de Calatrava, del Consejo, Junta de Guerra y Cámara de Indias de Su Majestad, su secretario de Estado y del Despacho Universal de Carlos II. Falleció el 24 de abril de 1713. ${ }^{33}$

Por último, cabe destacar a Juan Antonio Romeo, marqués de Erendazu. Quizás se trate del caso más interesante por el trabajo realizado por Roberto Quirós, quien ha dedicado esfuerzo por construir su más estrecha trama de colaboradores. ${ }^{34}$ Como se puede observar en su trabajo, las procedencias de estos personajes, como Baztan, Vitoria o Vizcaya, muestran que las lealtades no provienen de los territorios, sino de las propias familias y es ahí donde se debe indagar más.

Romeo (1660-1717) nació en la villa navarra de Miranda de Arga. ${ }^{35}$ En 1675, comenzó a servir en Lombardía, tanto en las armas como en las oficinas, bajo la protección del conde de Melgar, que por entonces era gobernador general de Milán. Bajo su manto llegó a alcanzar el grado de capitán de caballos corazas, ser su secretario personal y de la mano de Carlos II, la merced de una plaza de ayuda de cámara supernumerario, con salario de quinientos cincuenta ducados anuales (1697). ${ }^{36}$

Posteriormente, ascendió a oficial de decretos de la Secretaría del Despacho Universal (1698), secretario de Justicia en la Cámara de Castilla y secretario de la negociación de Milán en el Consejo Supremo de Italia (1699). La confianza hacia su persona fue en aumento y Felipe V le otorgó el negociado de Sicilia, que Romeo mantuvo entre 1703 y 1705.

Sin embargo, su escasa relación con José Grimaldo, el marqués de Mejorada y la camarilla francesa paralizó su progresión y nuevos nombramientos en el nuevo orden creado por Felipe V. Todo ello respondió a su velada fidelidad a los Habsburgo, por lo que en el verano de 1706 decidió abandonar la corte de Madrid y seguir la retirada manchega y valenciana de las tropas aliadas.

Con Carlos III en Valencia, el conde de Oropesa actuó por la constitución de una Secretaría de Estado, que sirviera de apoyo principal y consejero del monarca. Finalmente, dicha secretaría se fundó con dos negociados paralelos: Península Ibérica y asuntos de Italia. En este último se colocó al frente a Romeo, por lo que comenzó a ser uno de los ministros con mayor importancia en la corte austriaca. ${ }^{37}$

$\mathrm{Su}$ poderosa posición le posibilitó rodearse de familiares y hechuras, patrocinándolos en espacios importantes de gobierno. Sus más estrechos socios estuvieron bajo su mando en la secretaría de Estado de Italia y en la Junta de esta parte de la Monarquía: Juan Antonio Alvarado y Colomo, ${ }^{38}$ vizcaíno Carlos Eguía, Pedro Jaurrieta y Landa, ${ }^{39}$ el navarro Antonio de Vergara y Gaviria, por ejemplo. Aunque

\footnotetext{
${ }^{32}$ Era hijo y heredero de Juan Bautista de Larrea, caballero de la Orden de Santiago y secretario de Felipe IV. AHN, Órdenes Militares, Calatrava, ex 1361, año 1667.

${ }^{33}$ Casó con Teresa Francisca de Mudara Herrera, natural de Madrid. AHN, Órdenes Militares, Casamiento, Calatrava, ex 480, año 1692.

${ }^{34}$ QUIRÓS, 2017, 135-166; QUIRÓS, 2018.

${ }^{35}$ AHN, Órdenes Militares, Expedientillos, N.4837, año 1681.

${ }^{36}$ QUIRÓS, 2017, 135-166; QUIRÓS, 2018.

${ }^{37}$ QUIRÓS, 2017, 135-166.

38 Aunque nacido en Madrid, por línea materna descendía de Miranda de Arga y Óbanos. Era hijo de Eugenio Alvarado, paje del conde de Monclova y administrador en Perú bajo la protección de este patrón. AHN, Órdenes Militares, Santiago, ex 312, año 1702.

${ }^{39}$ Nacido en Madrid, pero de origen navarro. QUIRÓS, 2017, 135-166.
} 
también contó con importantes colaboradores togados, financieros y militares, siendo el cabeza principal de los navarros leales a Carlos III: vizcaíno Francisco de Baraya y Larrabe, el doctor baztanés Juan Ángel Apezteguía y Francisco Antonio Navarro, ${ }^{40}$ que llegó a ser secretario de los negociados españoles de la secretaría del Consejo de Estado.

En otros ámbitos, bajo el patrocinio de Romeo y al servicio de Carlos III, estuvieron otras personalidades con origen en el reino de Navarra. Su pariente Miguel Jerónimo Antillón y Novar, ${ }^{41}$ que como sus hermanos se trasladó a Barcelona para ponerse a los pies de Carlos III, fue elevado por su mano a consejero de capa y espada del supremo de Aragón.

Por su parte, Pedro Morrás y Mauleón, oriundo de la merindad de Estella, ${ }^{42}$ pasó al ejército de Cataluña con una compañía de caballos corazas valones, donde asistió a la caída de Barcelona de las manos francesas. En 1702 pasó a Portugal y se dedicó a la constitución de los primeros regimientos españoles de Carlos III. Por influencia de Romeo se le envió a la corte de Turín como enviado extraordinario, quedándose en la corte piamontesa, siendo honrado con el marquesado de Honrubia, desde 1707 hasta $1713 .{ }^{43}$

Asimismo, Simón de Iturrigaray, ${ }^{44}$ en el valle de Baztan, fue un hombre de negocios que se instaló en San Sebastián y Pamplona. En 1706, huyó a la corte de Barcelona "por afecto" a la casa de Austria y en 1710 recibió el oficio venal de dispensador de azúcares en Nápoles, donde vivió durante un tiempo.

Agustín Colomo, oriundo de Miranda de Arga y pariente de Romeo, en su juventud se había afincado en Panamá, donde desarrolló una amplia actividad económica. Durante la guerra de sucesión, y en relación con Romeo, se convirtió en un importante agente secreto al servicio de Carlos III. Además, también de la mano del secretario del Despacho, propuso desembolsar 16.000 reales de a ocho para la ayudar a la defensa de Cataluña. ${ }^{45}$

En 1711, fue enviado a la corte imperial como legado extraordinario $y$, posteriormente, consiguió de forma el marquesado de Cabanillas del Campo. Al año siguiente, se encaminó a Utrecht para entregar las instrucciones a los plenipotenciarios de Carlos III. Desde esta ciudad informó a Romeo sobre la evolución del congreso. ${ }^{46}$

\section{Misma familia $y$ distintos resultados: los intereses de Villarreal de Bérriz- Andicano}

A través de una metodología en clave de red social, nos detendremos en una de estas familias que se encuentran en la encrucijada de la guerra, para conocer desde dentro, y gracias a su correspondencia particular, cómo fueron actuando según se fueron presentando las oportunidades o los problemas durante la Guerra de Sucesión.

Nos centraremos en Sebastián Villarreal, Juan Bautista Villarreal (Gámiz, 1655), ${ }^{47}$ Pedro Bernardo Villarreal de Bérriz y Andicano (Mondragón, 1669), y Mateo Nicolás de

\footnotetext{
${ }^{40}$ Nacido en Sangüesa.

${ }^{41}$ SEGURA, 2014, 665-699.

${ }^{42}$ AHN, Órdenes Militares, Santiago, ex 5562, año 1694.

${ }^{43}$ QUIRÓS, 2017, 135-166.

${ }^{44}$ Fue abuelo de José de Iturrigaray, hombre de Godoy y virrey de México entre 1803 y 1808.

${ }^{45}$ QUIRÓS, 2017, 135-166.

${ }^{46}$ Ibídem, 135-166.

${ }^{47}$ AHN, Órdenes Militares, Santiago, ex 8.941, año 1681.
} 
Aranguren y Andicano, tres hermanos con distintos padres y madres que formaban parte de familias muy conectadas con los diferentes espacios de poder de la Monarquía, con miembros tanto en los negocios del hierro con Indias como en los cargos en la administración real.

El progenitor de dos de ellos fue Pedro Villarreal y Gamboa (Frúniz, 1628-1669), señor de Bérriz, que guardaba poderosas relaciones, especialmente con la casa Medinaceli, lo que le facilitó la entrada de sus hijos en diferentes espacios elitistas muy ligados al gobierno de la Monarquía de Carlos II, además de disfrutar de importantes posiciones en el Señorío de Vizcaya.

Por su parte, María Sáez de Andicano Celaá (Mondragón, 1627), ${ }^{48}$ madre de los otros dos, fue azafata de la infanta Margarita Teresa de Austria, prometida del futuro emperador Leopoldo I y su hermano de Juan, el primer conde de Monterrón, llegó a ser en 1680 consejero de Castilla. ${ }^{49}$

\subsection{Pedro Bernardo Villarreal de Bérriz y la fabricación de armas por asiento}

Tras recibir una delicada educación en la corte y en la Universidad de Salamanca, Pedro Bernardo contrajo matrimonio en 1694 con Mariana Rosa de Bengolea, principal heredera de su casa. Desde entonces, residió en la torre de Uriarte, sita en Lequeitio y se colocó al frente de los bienes que heredó de su padre, así como del patrimonio de los Bengolea, basado principalmente en ferrerías, montes y el generado por grandes negocios relacionados con el hierro en Indias.

Como hombre principal de Vizcaya, tuvo un papel fundamental en las negociaciones llevadas a cabo por parte de los propietarios ferrones para la revitalización del comercio del hierro, incluso el 7 de julio de 1700 fue representante del Señorío en unas conferencias desarrolladas en Oñate, Guipúzcoa.

Sin embargo, más allá del orden institucional, en coordinación con sus parientes y amigos de Guipúzcoa y Vizcaya, manejó sus propios hilos para buscar la mejor solución para los suyos. Uno de sus máximos colaboradores fue su amigo Antonio de Idiáquez y Eguía. ${ }^{50}$

En un momento en el que predominó la economía de guerra, los negocios orientados a los intereses bélicos supusieron una posibilidad para estos comerciantes. Los contratos firmados con la Corona (especialmente con asientos) fueron los más arriesgados y rentables, y para su consecución hubo de disfrutar con influyentes apoyos en la corte y en la alta administración. No hay que olvidar que las posibilidades de pago del rey fueron muy amplias (más allá de lo estrictamente económico) y estos servicios fueron también recompensados con empleos en la alta administración y palacio y honores (como títulos nobiliarios o hábitos de las órdenes militares para estas familias), pero también, por ejemplo, con la superioridad de ciertos mercados o preponderancia en territorios concretos.

Un punto importante fue que mantuvieron grandes apoyos en la alta administración, contactos fundamentales para poder concretar estos proyectos de gran envergadura, gozando así tanto de la confianza del rey como de sus más estrechos colaboradores

\footnotetext{
${ }^{48}$ AHN, Órdenes Militares, Santiago, ex 523, año 1665.

49 AHN, Órdenes Militares, Santiago, ex 416, año 1683 y ex 415, año 1676; TOLA de GAYTÁN, 1947, 145; FAYARD, 1982, 45, 303.

${ }^{50}$ RUIZ DE AZÚA, 1990, 40 y 70-73; 152.
} 
dedicados al ramo de la Guerra y la Hacienda, como Juan Orry, el marqués de Canales o, desde 1705, José Grimaldo. Asimismo, a través de los años, esta familia había dedicado buena parte del capital acumulado de los negocios en América en la ampliación y mejora de sus bienes raíces (principalmente montes y ferrerías), por lo que sus industrias pudieron elaborar productos de notable calidad y según las exigencias del mercado, lo que les hizo especialmente competitivos.

Pedro Bernardo concentró sus esfuerzos para conseguir fabricar municiones en las ferrerías de Bengolea, ya que la fabricación de armas para el rey se efectuó en la mayoría de las ocasiones en el marco de la firma de un asiento entre el rey y particulares. Así ocurrió con las factorías principales de la Península Ibérica. ${ }^{51}$ En ese momento Juan Orry estaba impulsando la creación de la Tesorería Mayor de Guerra y la división de la Secretaría del Despacho en los negociados de Guerra y Hacienda y "de todo lo demás". El hombre principal con la responsabilidad en los asientos de guerra y las reales fábricas de armas sería el marqués de Canales.

Para ello, contó con colaboración de parientes y allegados sitos en las provincias vascas, en una acción colectiva en diversos ámbitos, como pudo ser la propia participación en estos negocios a través de las inversiones económicas, la aportación de un apoyo logístico o también con cobertura de carácter político, especialmente ante posibles conflictos con diputaciones, concejos o ante las asambleas instituidas por los ferrones para concretar los actos en busca de la salida de la crisis comercial del hierro. Pedro Bernardo fue el canalizador de estas iniciativas y propuestas llegadas por sus colaboradores de Vizcaya, que como patrón y máximo promotor de estos proyectos, intentó conseguir el mayor beneficio para los suyos. ${ }^{52}$

Tras un intento fallido en 1703, las negociaciones de Pedro Bernardo en la corte madrileña dieron sus frutos. En mayo de 1705 cerró con Felipe V un asiento por seis a ocho años para "hacer en sus ferrerías de Bengolea, que son las mejores de todo aquel Señorío la fabricación de bombas, carcasas, balas, granadas y todos los demás pertrechos de guerra que se fabrican en las oficinas de Eugui, en Navarra y en las de Liérganes, obligándose debajo de ciertas condiciones a dar cada año de tres hasta seis mil quintales [cada uno de a cien libras castellanas de a dieciséis onzas cada una], quince reales de vellón más barato cada quintal de lo que cuestan a v.m. en las dichas fábricas de Navarra (...)" ${ }^{53}$ El contrato empezó a correr desde el primer día de junio de ese mismo año y el rey le debería entregar prontamente mil doblones de a dos escudos de oro cada uno de ayuda, para levantar los ingenios, hacer hornos, moldes y otras cosas necesarias.

El señor de Bérriz decidió contratar a Juan Cubria, ingeniero de las factorías de Liérganes, para que adaptara las ferrerías de Bengolea a la nueva producción de armamentos y de contratar el personal necesario. También se comprometió a transportar su producción a las plazas y destinos ordenados por la Secretaría del Despacho de Guerra y Hacienda (Vitoria, Valladolid o Tortosa), con el cobro de unas tarifas que finalmente concretó el rey, tras una rebaja de los precios que él mismo había presupuestado al inicio.

La envergadura y condiciones asumidas por Pedro Bernardo Villarreal de Bérriz en este asiento es una excelente muestra de su capacidad de acción, de su poder económico,

\footnotetext{
${ }^{51}$ CASTRO, 2004, 186.

${ }^{52}$ Carta de Nicolás de Ubilla a Pedro Bernardo de Villarreal de Bérriz, Marquina, 19 de enero de 1703. ATU, leg. XXI, 1-31-a, b, c, d, e.

${ }^{53}$ El 24 de abril de 1705 Pedro Bernardo Villarreal de Bérriz había elevado el memorial con las condiciones para el asiento. La publicación se concretó en mayo. RUIZ DE AZÚA, 1990, 175.
} 
así como de su influencia en la corte, lo que le posibilitó reorientar las inversiones de la casa en momentos de profunda crisis general.

Por último, el contrato firmado con la Corona le concedió grandes privilegios (como a cualquier otro asentista), pero también tuvo la oportunidad de extender estas prerrogativas a sus clientes y oficiales de sus ferrerías, ya que tuvieron por trabajar bajo este asiento un estatus idéntico a los que produjeron en fábrica real. De este modo, se extendió aún más el ascendiente de los Villarreal de Bérriz entre los vecinos de su comunidad y los del Señorío. ${ }^{54}$

\subsection{La frustración de Mateo Nicolás de Andicano: la Real Fábrica de Armas de Cantabria}

En 1703, y paralelamente a las gestiones de su hermano Pedro Bernardo, Mateo Nicolás de Aranguren y Andicano comenzó sus gestiones en la corte para conseguir la superintendencia de las Reales Fábricas de Armas de Cantabria, con el objetivo también de conseguir el traslado su sede principal, ubicada en Placencia, a su villa natal de Mondragón.

Su habilidad en las gestiones en la corte le llevó a conseguir el 3 de noviembre de 1703, por mano del marqués de Canales, una instrucción de Felipe V para que realizara una inspección e informe del estado de dichas fábricas (de todo lo que fuera allí más conveniente para el real servicio). ${ }^{55}$

La designación como visitador de Mateo Nicolás en las Reales Fábricas de Cantabria interrumpió la administración ejercida hasta entonces por parte de la familia Zavala. En aquel momento, José Francisco de Zavala, que a la vez era el titular de su casa $^{56}$, viajó a la corte para activar a sus contactos en su afán por prolongar el manejo de las factorías, aunque todos estos intentos fueron inútiles. ${ }^{57}$

Desde un principio, aprovechando la autoridad que le otorgó las reales órdenes recibidas por mano de Canales, quiso eliminar competidores y en sus informaciones resaltó el maltrecho estado de las factorías y los continuados fraudes fiscales que se habían cometido bajo su mandato y el de sus antecesores. ${ }^{58}$

En un principio, los esfuerzos de Mateo Nicolás dieron sus frutos y se situó como el principal delegado real en la fábrica de armas. Por este motivo, hubo de presentar la nueva planta para las Reales Fábricas de Armas, poniendo las bases del nuevo gobierno de las factorías. ${ }^{59}$

Sin embargo, a pesar de estos triunfos iniciales, Mateo Nicolás pronto perdió estas posiciones preponderantes.

\footnotetext{
${ }^{54}$ Ibídem, 176-177.

${ }^{55}$ Copia de la carta de Mateo Nicolás de Aranguren y Andicano a Miguel Francisco Salvador, Mondragón, 17 de septiembre de 1705. AHN, Estado, leg. 276; Carta de Mateo Nicolás de Aranguren y Andicano a Miguel Francisco Salvador. Mondragón, 17 de septiembre de 1705. AHN, Estado, leg. 276.

${ }^{56}$ Carta de José de Zavala a José Grimaldo. Villafranca de Guipúzcoa, 13 de agosto de 1708. AHN, Estado, leg. 356.

${ }^{57}$ Carta de Antonio Francisco Vélez de Idiáquez y Alzolarás a José Grimaldo. Azcoitia, 11 de octubre de 1707. AHN, Estado, leg. 305.

${ }^{58}$ Carta de Mateo Nicolás de Aranguren y Andicano a José de Grimaldo, Mondragón, 6 y 11 de agosto de 1705. AHN, Estado, leg. 276.

${ }^{59}$ Carta de Mateo Nicolás de Aranguren y Andicano a José Grimaldo, Mondragón, 4 de septiembre de 1705. AHN, Estado, leg. 276.
} 
El retorno de la Princesa de los Ursinos a la corte conllevó la reactivación del programa de reformas iniciadas desde el comienzo del reinado, así como la ejecución de nuevos nombramientos. Uno de los más importantes fue la designación de José Grimaldo como nuevo secretario del Despacho de Guerra y Hacienda, relegando al marqués de Canales de estas funciones. Igualmente, la necesidad de aprovisionar al ejército de armas y todo tipo de municiones provocó que Juan Orry decidiera nombrar a otro visitador en las reales fábricas. Quizás los deseos de mejora de la producción, así como la poca fiabilidad que pudo ofrecer Mateo Nicolás en su posible organización de los talleres (muy ligadas con sus negocios particulares), provocaron el llamamiento el 8 de septiembre de 1705 de Miguel Francisco de Salvador (un hombre muy relacionado con el equipo de gobierno de Felipe V) para “indagar la conducta del superintendente de las fábricas y sus ministros, reconocer los almacenes y oficinas, entregarme las armas, saber las que se han hecho y el paradero que han tenido, como también lo que se debe a los operarios y otros puntos concernientes al todo de este negocio". ${ }^{60}$

Entonces, Miguel Francisco comprendía que su estancia en Guipúzcoa sería breve, igual que su misión, y que encontraría a Mateo Nicolás, a quien conocía personalmente, a un fiel colaborador. Sin embargo, Aranguren se desentendió del nuevo visitador, negándole toda colaboración, a la vez que continuó elevando informes a Grimaldo (en la continuación de la delegación contraída por mano de Canales) que desprestigiaba la labor del nuevo agente enviado desde la corte: “(...) Dificulto mucho que D. Miguel Francisco pueda descubrir lo que importa y se desea saber porque se halla en tierra extraña y rodeado de los mismos ministros interesados, con que será factible se encuentren los informes y consiguientemente quede la materia en opiniones (será lastimosa cosa que por este medio se falte al servicio de Dios y del rey). Debo asegurar a v.s. que mis informes son ciertos, claros como la luz de medio día (...)" y "suplico a v.s. rendidamente favorezca mi causa porque entré en esta dependencia y por orden del rey, sin haberla solicitado y solo supe de ella cuando me hallé el real despacho y sobre lo que he trabajado y gastado no será razón, me vea en necesidad de retirarme a un desierto por huir de indignación de los laborantes y otros que se persuaden". ${ }^{1}$

Desde la Secretaría del Despacho de Guerra y Hacienda, y en varias ocasiones, se ordenó a Mateo Nicolás que no entorpeciera la labor del nuevo visitador de las fábricas. ${ }^{62}$ Ante la desobediencia, Miguel Francisco de Salvador no salía de su asombro ${ }^{63}$ y decidió actuar contra la insubordinación del mondragonés con toda la autoridad que le confería el respaldo de Grimaldo, de Orry y de los otros miembros de este equipo de gobierno.

Por una parte, se alió con Sancho de Miranda, ministro de S.M. en Guipúzcoa, que le informó de la personalidad y de los intereses verdaderos de Mateo Nicolás. ${ }^{64}$ Asimismo, decidió enviar un duro informe con la intención de apartarle de estos cometidos y de este modo finalizar con un complejo y desagradable episodio que

\footnotetext{
${ }^{60}$ Carta de Miguel Francisco Salvador a Mateo Nicolás de Aranguren y Andicano, Placencia, 16 de septiembre de 1705. AHN, Estado, leg. 276.

${ }^{61}$ Carta de Mateo Nicolás de Aranguren y Andicano a José de Grimaldo, Mondragón, 24 de septiembre de 1705. AHN, Estado, leg. 276,

${ }^{62}$ Ambos billetes, de octubre de 1705. AHN, Estado, leg. 276.

${ }^{63}$ Carta de Miguel Francisco Salvador a José Grimaldo, Tolosa, 22 de septiembre de 1705. AHN, Estado, leg. 276.

${ }^{64}$ Carta de Miguel Francisco de Salvador a José de Grimaldo. Placencia, 5 de octubre de 1705. AHN, Estado, leg. 276.
} 
entorpecía el servicio al rey y su propio crédito, en unos momentos de necesidad de mejorar la gestión y producción de las Reales Fábricas de Armas. ${ }^{65}$

Para argumentar con mayor fundamento sus acusaciones, el 27 de septiembre Miguel Francisco congregó a Juan Romarate, Domingo de Mauregui menor en días, Antonio de Oleada y Juan Bautista de Ugarte, todos vecinos de Placencia, ante Ignacio Aguirre, escribano de la villa de Mondragón, para que testificarían "sobre algunos procedimientos de D. Mateo Nicolás de Aranguren" y "dijeron y declararon que el día siete de agosto y ocho del presente mes y año publicó D. Mateo Nicolás de Aranguren y Andicano, caballero de la orden de Santiago, vecino de esta dicha villa, que tenía despachos de Su Majestad para ser gobernador de las Armas de la villa de Placencia y en regocijo de esta nueva salió con tamboril y hubo danza de festejo entre muchos oficiales de las Reales Fábricas y otros. Y asimismo dijeron que eran noticiosos de que en diferentes ayuntamientos el dicho $\mathrm{D}$. Mateo Nicolás pidió que la villa saliese a pedir que las pruebas de armas de dicha fábrica se hiciesen en esta villa (y a mayor abundamiento se remiten a los decretos de dichos ayuntamientos), lo cual no se le concedió por parecer que su pretensión era excusada y que no llevaba fundamento (...)". ${ }^{66}$

La comisión de Miguel Francisco de Salvador se prolongó a lo largo de 1706 y 1707, hasta que definitivamente fue nombrado superintendente de las Reales Fábricas de Cantabria el 7 de diciembre de 1707. Hasta este momento Mateo Nicolás siguió intentando hacer valer su posición ante José Grimaldo, y en el verano de este año aún solicitó a sus apoyos en la corte para que intercedieran en su problema personal. ${ }^{67}$ Estos últimos intentos no tuvieron ninguna incidencia y Mateo Nicolás quedó completamente desplazado de cualquier gestión referida a las manufacturas reales, quedando Salvador al frente de las mismas hasta prácticamente el final de la Guerra de Sucesión.

\subsection{Juan Bautista de Villarreal: El servicio a Medinaceli le apartó de la corte}

Pedro de Villarreal y Gamboa guardó poderosas relaciones con la casa Medinaceli, lo que le facilitó la entrada de sus hijos en diferentes espacios elitistas muy ligados al gobierno de la Monarquía de Carlos II.

Uno de sus hijos, ${ }^{68}$ Juan Bautista Villarreal y Frúniz (Gámiz, 1655), fue colocado cuando contaba con quince años de edad camino a Flandes para servir como paje al conde de Fernán Núñez. Tras una temporada en esos estados, continuó con esta ocupación en Madrid, pero esta vez bajo el mando de Luis Francisco de la Cerda, marqués de Cogolludo. ${ }^{69}$

Posteriormente, continuando con su servicio a dicha casa, acompañó a Luis Francisco de la Cerda (ya como duque de Medinaceli) cuando este fue nombrado en los últimos años de la década del siglo XVII virrey y capitán general de Nápoles, desempeñando bajo su servicio el empleo de camarero mayor.

\footnotetext{
${ }^{65}$ Carta de Miguel Francisco Salvador a Juan Orry. Placencia, 28 de septiembre de 1705. AHN, Estado, leg. 276.

${ }^{66}$ AHN, Estado, leg. 276.

${ }^{67}$ Cartas de Mateo Nicolás de Aranguren y Andicano a José Grimaldo, Mondragón, 6 de julio de 1707 y 10 de agosto de 1707. AHN, Estado, leg. 305.

${ }^{68}$ El señor de Bérriz colocó a sus hijos Antonio y Sebastián Villarreal y Lezama como pajes del marqués de Heliche, desarrollando después una importante carrera. AHN, Órdenes Militares, Santiago, ex 8.941, año 1681

${ }^{69}$ AHN, Órdenes Militares, Santiago, ex 8.941, año 1681.
} 
En Italia, Juan Bautista Villarreal y Gamboa se convirtió en un hombre destacado por su conocimiento de las ciencias exactas y el buen manejo de varios idiomas. Allí estableció importantes relaciones como el general de los jesuitas Tirso González, Carlo Colonna, mayordomo de Inocencio XII y cardenal, el arzobispo de Salerno y antiguo general de los franciscanos fray Bonaventura Poerio o el cardenal Lauria, así como a José de Armendáriz, el futuro marqués de Castelfuerte. Fue admitido junto a su señor el duque de Medinaceli en la Academia de los Arcades y una de sus obras la dedicó a Juan Manuel Fernández Pacheco de Acuña, duque de Escalona y marqués de Villena, que fue virrey de Nápoles de 1702 a 1707, por lo que también pudo mantener algún vínculo con este defensor de la causa de Felipe V.

Tras el fallecimiento de Carlos II, Medinaceli apoyó a Felipe V, aunque siempre quiso mostrarse contrario a convertir a España en un instrumento al servicio de la ambición francesa. En 1702, el duque regresó a la corte de Madrid junto con sus más estrechos colaboradores, entre ellos Juan Vélez de León, su gentilhombre y el propio Juan Bautista de Villarreal. Ya en España, sus circunstancias cambiaron por completo por las complicadas circunstancias políticas que se estaban viviendo por entonces: el clima de sospecha general hacia los Grandes y el malestar de estos por la intromisión francesa en el gobierno de la monarquía. Abandonó su empleo de presidente del Consejo de Indias y empezó a mostrar su descontento ante Amelot y el propio rey por los derroteros que estaban tomando las medidas reformadoras que se estaban llevando a cabo. Con todo, fue nombrado ayo del príncipe de Asturias (1709).

Sin embargo, Medinaceli fue perdiendo la confianza del rey, siendo el 15 de abril de 1710 arrestado y juzgado en secreto, por causas que no se hicieron públicas. Fue condenado a prisión, estuvo primero en el alcázar de Segovia, de donde se le trasladó a Fuenterrabía en septiembre, ante el avance de las tropas aliadas, y dos meses después a la fortaleza de Pamplona. Falleció poco después. ${ }^{70}$

En este juego de intereses políticos y personales quien ejecutó el arresto fue un estrecho amigo de la familia de los Villarreal de Bérriz: Juan de Idiáquez, sargento mayor de las guardias reales. El 15 de aquel mes de abril de 1710, Medinaceli fue apresado por su desafección al rey Borbón. Tras reunirse con Felipe $\mathrm{V}$ en palacio, fue ordenado a que bajara a la covachuela, donde le esperaba Grimaldo junto con Idiáquez, el cual había recibido orden verbal del rey llevarle reo. Fue él quien acompañó al duque al parque, donde aguardaba el irlandés Patricio Laules, subteniente de guardias de corps, con una compañía de caballos formada para transportarlo como prisionero al alcázar de Segovia. ${ }^{71}$

Como hemos visto, la carrera de Juan Bautista estuvo ligada a la figura de Medinaceli, y también sucedió en estos momentos de crisis política y social. De este modo, en 1716, se le abrió juicio por acompañar al archiduque a Barcelona. En su memorial para solicitar el perdón real, entre otras cuestiones, se defendió explicando que se vio conminado a trasladarse a Barcelona con el Archiduque a petición del conde de Gálvez, pero que ante el inminente peligro de caer la ciudad en manos de Felipe V optó por refugiarse en la casa del prior de la Colegiata de Santa Ana en lugar de trasladarse a Viena, como le animaban a hacerlo muchos nobles seguidores de Carlos III. Finalmente, fue obligado a retirarse a casa, como así hizo el 15 de julio de 1716, instalándose en la torre de Uriarte, con su hermano Pedro Bernardo. Desde allí se carteó con otros eruditos

\footnotetext{
${ }^{70}$ KAMEN, 1974.

${ }^{71}$ PEÑALOSA, 2001, 148.
} 
italianos y de la corte de Madrid, tratando diferentes temas científicos participando en las tertulias que organizaron en la torre de Uriarte. Falleció el 31 de mayo de 1729, dejando como heredero universal a su hermano, el señor de Bérriz. ${ }^{72}$

\section{Conclusiones}

Durante la Guerra de Sucesión, las familias de las elites vascas y navarras se repartieron desigualmente entre el bando de los Borbones y de los Austrias. Aunque una amplia mayoría se decantó por Felipe V, también hubo otras que decidieron ser leales a Carlos III, desarrollando una labor importante en las administraciones de cada uno de los monarcas.

Desde una metodología de red social, hemos podido comprobar cómo la conformación de estos cuadros está muy relacionada con los vínculos que estas familias y sus miembros mantenían con personajes poderosos de la corte de Madrid. Estas posturas sobrellevaron la movilización de personas y recursos fundamentales para el transcurso del conflicto bélico. Así se ve con Juan de Idiáquez y Juan Antonio Romeo y sus actuaciones a favor de cada uno de los pretendientes.

Sin embargo, estos agentes del rey fueron reconstruyendo sus lazos a la vez que se fue redefiniendo el gobierno de la Monarquía, muchas veces diluidas con sus propias necesidades, emanadas de los acontecimientos bélicos y las necesidades obligadas para la victoria final de la guerra.

Los resultados obtenidos por los hermanos Villarreal y Andicano para la capitalización de la fabricación de armas en las provincias vascas y mantener sus posiciones en la corte fueron desiguales y demuestra que incluso en una misma familia, los vínculos manejados por cada uno de sus miembros pueden determinar sus carreras, a la vez que las políticas de la casa se dirigirán a la preservación y mejora de la misma, especialmente en momentos de incertidumbre.

Por lo tanto, el triunfo general también conllevó pequeños fracasos particulares que fueron parte de él, pero tampoco supusieron un parón general, ya que siguieron participando de la red capitalizando y recogiendo, por otro lado, los frutos de estas posiciones preponderantes. Mateo Nicolás se le puede considerar como un personaje tipo de estas dinámicas y políticas familiares de estas elites.

En un principio, parecería algo extraño porque eran hermanos y manejaban los mismos resortes para la concreción de sus proyectos, con parientes y amigos situados poderosamente en Madrid, donde colaboraban y eran ejecutores de las políticas llevadas a cabo por el nuevo monarca. Sin embargo, estar bien relacionado, con amigos y parientes insertos en una dinámica exitosa repleta de cargos, influencias, capitales, honores, y en definitiva, poder, no implicó trayectorias marcadas por éxitos y promociones.

\section{REFERENCIAS BIBLIOGRÁFICAS}

Archivos

Archives du Service Historique de l'Armée de Terre, Paris (SHAT).

${ }^{72}$ SAAVEDRA ZAPATER, 2000, 469-497; GUERRERO ELECAILDE, 2012. 
Série A:

1885, ex 31 bis; 277.

Archivo Histórico Nacional, Madrid (AHN).

Consejos:

Concursos, Secuestros, 51213.1.Estado:

Leg. 276; 305; 356; 391; 402.

Carlos III, ex 510, año 1791 .

Órdenes Militares:

Calatrava, ex 1361, año 1667.

Santiago, ex 523, año 1665; ex 415, año 1676; ex 8.941, año 1681; ex 416, año 1683; 5562, año 1694; ex 312, año 1702.

Casamiento, Calatrava, ex 480, año 1692.

Expedientillos, N.4837, año 1681.

Archivo de la Torre de Uriarte, Lekeitio, Bizkaia (ATU).

Leg. XXIV, 3-8-c, d; XXI, 1-31-a, b, c, d, e.

Fuentes Secundarias

ALBAREDA, Joaquim, La Guerra de Sucesión de España (1700-1714), Barcelona, 2010.

ANDÚJAR, Francisco, "Élites de poder militar: las guardias reales en el siglo XVIII", en CAStellano, Juan Luis, DedieU, Jean-Pierre y LóPEZ-Cordón, María Victoria (eds.), La pluma, la mitra y la espada. Estudios de Historia Institucional de la Edad Moderna, Madrid, Marcial Pons, 2000, 65-94.

- Francisco, "La corte y los militares en el siglo XVIII", Estudis:Revista de Historia Moderna, 27, 2001, 91-122.

BADORREY, Beatriz, Los orígenes del Ministerio de Asuntos Exteriores (1714-1808), Madrid, Ministerio de Asuntos Exteriores, 1999.

BARRIOS, Feliciano, El Consejo de Estado de la Monarquía española, 1521- 1812, Madrid, Consejo de Estado, 1984,

CASTELLANO, Juan Luis, "El gobierno en los primeros años del reinado de Felipe V: la influencia francesa", en Actas del Congreso Nacional Felipe Vde Borbón, 1701-1746. Congreso Nacional Felipe V de Borbón. San Fernando (Cádiz), Córdoba, Universidad, 2002, 129-142.

CASTRO, Concepción de, A la sombra de Felipe V. José de Grimaldo, ministroresponsable (17031726), Madrid, Marcial Pons, 2004.

CLAVERO, Bartolomé, Razón de Estado, razón de individuo, razón de Historia, Madrid, Centro de Estudios Políticos y Constitucionales, 1991, 15-59.

DEDIEU, Jean-Pierre, "La Nueva Planta en su contexto. Las reformas del aparato del Estado en el reinado de Felipe V", Manuscrits: Revista d'històriamoderna,18, 2000, 113-139.

DESOS, Catherine, Les Français de Philippe V. Un modèle nouveau pour gouverner l'Espagne (1700-1724), Estrasburgo, Presses Universitaires, 2009.

DUBET, Anne, "¿La importación de un modelo francés?: acerca de algunas reformas de la administración española a principios del siglo XVIII", Revista de Historia Moderna. Anales de la Universidad de Alicante, 25, 2007, 207-234.

"La nueva política crediticia de la Corona a principios del sigloXVIII: la creación del Tesorero Mayor de guerra en España (1703-1706)",Studia historica. Historia moderna, 30, 
2008, 191-216.

ESCUDERO, José Antonio, Los orígenes del Consejo de Ministros. La Junta Suprema de Estado, tomo I, Madrid, Edit. Nacional, 1979.

FAYARD, Janine, Los miembros del Consejo de Castilla (1621-1746), Madrid,Siglo XXI, 1982.

GIRARDOT, barón de (ed.), Correspondencia de Luis XIV con M. Amelot, su embajador en España. 1705-1709, Alicante, Universidad de Alicante, 2012.

GONZÁLEZ CRUZ, David, "Espacios y territorio en la propaganda y en los discursos durante los conflictos bélicos: la Guerra de Sucesión en España yAmérica”, E-Spania, 14, 2012.

GONZÁLEZ MEZQUITA, María Luz, Oposición y disidencia en la Guerra de Sucesión Española. El Almirante de Castilla. Valladolid, Junta de Castilla y León, 2007.

GUERRA, François-Xavier, "El renacer de la historia política: razones y propuestas", en GALLEGOS, José Andrés (dir.), New History, Nouvelle Historie. Hacia una Nueva Historia, Madrid, Universidad Complutense, 1993, 243-264.

GUERRERO ELECALDE, Rafael, "Las cábalas de los "vizcaínos". Vínculos, afinidades y lealtades en las configuraciones políticas de la primera mitad del siglo XVIII: La red del marqués de la Paz”, en SORIA MESA, Enrique y MOLINA RECIO, Raúl (eds.), Las élites en la época Moderna: La Monarquía Española. Tomo II, Familia y redes sociales, Córdoba, Universidad de Córdoba, 2009, 247-258.

"Los hombres del rey. Redes, poder y surgimiento de nuevas elites gobernantes durante la guerra de sucesión española (1700-1714)”, Revista Prohistoria, 13, 2010.

, "Gozan de la confianza del rey. Redes, políticas familiares y poder de los vizcaínos en la Corte de la primera mitad del siglo XVIII", en IMÍZCOZ, José María y OLIVERI, Oihane (coords.), Economía doméstica y redessociales en el Antiguo Régimen, Madrid, Sílex, 2010b, 145-176.

- Las elites vascas y navarras en el gobierno de la Monarquía borbónica: Redes sociales, carreras y hegemonía en el siglo XVIII (1700-1746), Bilbao, Universidad del País Vasco, 2012.

IMÍZCOZ, José María, "De la comunidad a la nación: élites locales, carreras y redes sociales en la España Moderna (siglos XVII-XIX)", en IMÍZCOZ, José María (coord.), Élites, poder y red social: las élites del País Vasco yNavarra en la Edad Moderna (estado de la cuestión y perspectivas), Bilbao, Universidad del País Vasco, 1996, 193-210.

, "Actores, redes, procesos: reflexiones para una historia más global", Revista de la Facultade de letras. História, III Série, Vol. 5, 2004,115-140.

IÑURRITEGUI, José María, Gobernar la Ocasión. Preludio político de la NuevaPlanta de 1707, Madrid, Centro de Estudios Políticos y Constitucionales, 2008.

KAMEN, Henry, La guerra de Sucesión en España, 1700-1715, Barcelona, Grijalbo, 1974.

LEÓN, Virginia y SÁNCHEZ BELÉN, Juan A., "Confiscación de bienes y represiónborbónica en la Corona de Castilla a comienzos del siglo XVIII", Cuadernos de Historia Moderna, 1998, 21, monográfico IV, 127-175.

LEÓN, Virginia, Entre Austrias y Borbones. El Archiduque Carlos y la monarquía de España (1700-1714), Madrid, Sigilo, 1993.

, El archiduque Carlos y los austracistas. Guerra de Sucesión y exilio, Barcelona, editorial Arpegio, 2014.

LÓPEZ-CORDÓN, María Victoria, "Instauración dinástica y reformismo administrativo", Manuscrits: Revista d'història moderna, 18, 2000, 93-111. 
LOYARTE, Adrián de, Viaje del rey Don Felipe V por Guipúzcoa, San Sebastián,1927.

LUZZI, Marcelo, "Entre la prudencia del rey y la fidelidad a su persona y dinastía: los grupos de poder en la corte de Felipe V durante la Guerra de Sucesión", Cuadernos dieciochistas, 15, 2014, 135-163.

MARTÍNEZ CARDÓS, José, Primera Secretaría de Estado. Ministerio de Estado. Disposiciones Orgánicas (1705-1936), Madrid, 1972.

MÚGICA, Serapio, Relación de diputados generales de Guipúzcoa desde 1550hasta 1877, San Sebastián, 1943.

PEÑALOSA, Isabel, El Alcázar de Segovia, prisión de estado la guerra de Sucesión española (1701-1714), Segovia, Patronato del alcázar, 2001.

QUIRÓS, Roberto, "La red navarra del marqués de Erenzadu y la Monarquía deCarlos III de Austria entre dinastismo y lógica clientelar", en ESTEBAN ESTRÍNGANA, Alicia (coord.), Decidir la lealtad: leales y desleales en contexto (siglos XVI-XVII), Alcalá, Universidad de Alcalá, 2017.

- Monarquía de Oriente. La corte de Carlos III y el gobierno de Italia durante la guerra de Sucesión española, Madrid, Macial Pons, 2018.

RODRÍGUEZ VILLA, Antonio, Don Diego Hurtado de Mendoza y Sandoval, Conde de la Corzana (1650-1720), Madrid, 1907.

RUIZ DE AZÚA, Estíbaliz, D. Pedro Bernardo Villarreal de Bérriz(1669-1740). Semblanzas de un Vasco Precursor, Madrid, Castalia, 1990.

SAAVEDRA, Juan C., "Entre el castigo y el perdón: Felipe V y los austracistas de la Corona de Castilla, 1706-1715", Espacio, tiempo y forma. Serie IV,Historia Moderna, 13, 2000, 469497.

STIFFONI, Giovanni, "Un documento inédito sobre los exiliados españoles en los dominios austriacos después de la guerra de Sucesión”, Estudis: Revista de historia moderna, 17, 1991, $7-56$.

TOLA DE GAYTÁN, marqués de, "Parientes mayores de Guipúzcoa. Señores de la casa solar y palacio de Zarauz, en Zarauz", BRSBAP, Año III, cuaderno1, 1947, 47-65.

VICENT LÓPEZ, Ignacio, "El discurso de la fidelidad durante la Guerra de Sucesión, Espacio, Tiempo y Forma, Serie IV, H. Moderna, 13, 2000, 61- 82. 